\title{
Urban Planning \\ in a Multicultural Society
}

The 1996 census reported that 18 per cent of Canadians were immigrants, settled primarily in the major urban areas of Toronto, Vancouver, Ottawa, and Montréal. While in the 1960s most immigrants came from Europe, today most immigrants come from Asia, Africa, the Caribbean, and South America. They bring with them a wide variety of languages, traditions, and ideas about society. What does it mean to be a planner in a multicultural city? Two sessions discussed the challenges that ethno-cultural diversity poses to urban planners.

Three observations emerged. First, the planning profession is reluctant to account for ethnicity in planning decisions, and is not fully prepared to meet the needs of a changing society. While planners must plan for the whole population, they often fail to take into account ethnicity and cultural changes, focusing instead on demographic data regarding age, income, and household characteristics. Second, planners must question the notion of a single "public interest." And third, they must recognize that ethnicity and culture affect planning in a variety of ways. For example:
$>$ The location of funeral homes can be the source of conflict.

$>$ Despite the assumptions of public participation practices, not everyone understands public notices, nor is everyone comfortable making representations to governments.

$>$ Large immigrant families find it difficult to get appropriate affordable rental housing and are often subject to discrimination.

$>$ Public spaces and recreational facilities are not always designed to meet the needs of immigrants, who may prefer a place to hang out informally, or to play bocce, basketball or soccer instead of hockey.

Speakers at the conference sessions made the following suggestions about meeting the challenges of multiculturalism:

$>$ We must recognize that planning is a value-based activity and replace the homogeneous "public interest". with new concepts of equity, community, and multiple publics.

$>$ We must collect and take into account the ethno-cultural census data.
$>$ We must improve our consultation strategies by reaching out to ethnocultural groups, and develop creative communication strategies involving partnerships, venues for events, translation, and graphics for written material.

$>$ We must increase the diversity of staff to reflect the values of the population in which we practice planning.

$>$ We must develop expertise in examining development applications for impacts on multicultural groups, just as we examine applications for environmental impacts.

The message is that planners have to find a new way of building the multicultural city. Planners are managers of change, and should be leaders in the search for solutions. Diversity is the basis of thriving communities. Neighbourhoods that broaden the economic range, expand the mix of age groups and household types, and open the door to racial integration, are desirable places to live. By being sensitive to changing values, planners can help build a better community.

\section{Sylvie Grenier, MCIP RPP}

Coordinator of the "multiculturalism" theme 